\title{
A Prospective, Multicenter Evaluation of Predictive Factors for Positive Surgical Margins After Nephron-Sparing Surgery for Renal Cell Carcinoma: The RECORd1 Italian Project
}

\author{
Riccardo Schiavina, ${ }^{1}$ Sergio Serni, ${ }^{2}$ Andrea Mari, ${ }^{2}$ Alessandro Antonelli, ${ }^{3}$
} Riccardo Bertolo, ${ }^{4}$ Giampaolo Bianchi, ${ }^{5}$ Eugenio Brunocilla, ${ }^{1}$ Marco Borghesi, ${ }^{1}$ Marco Carini, ${ }^{2}$ Nicola Longo, ${ }^{6}$ Giuseppe Martorana, ${ }^{1}$ Vincenzo Mirone, ${ }^{6}$ Giuseppe Morgia, ${ }^{7}$ Francesco Porpiglia, ${ }^{4}$ Bernardo Rocco, ${ }^{8}$ Bruno Rovereto, ${ }^{9}$ Claudio Simeone, ${ }^{3}$ Mario Sodano, ${ }^{3}$ Carlo Terrone, ${ }^{10}$ Vincenzo Ficarra, ${ }^{11}$ Andrea Minervini $^{2}$

\begin{abstract}
The early oncological goal of any partial nephrectomy (PN) is to achieve negative surgical margins (SMs). Several factors have been advocated as predictors of positive SMs (PSMs) after nephron-sparing surgery (NSS). In our study, age, upper pole tumor location, standard PN and Fuhrman 3/4 nuclear grade were found to be independent predictors of PSMs at multivariable analysis. Further evaluations are required to verify the oncological effect of the PSM on local and systemic recurrence.

Background: The purpose of this study was to evaluate the predictors of positive margins in one of the largest available prospective multi-institutional studies. Patients and Methods: We evaluated all patients who underwent NSS for radiologically diagnosed kidney tumors between January 2009 and December 2012 at 19 urological Italian centers (Registry of Conservative Renal Surgery [RECORd] project). Preoperative and anthropometric data, comorbidities, intraoperative and postoperative outcomes, and histological findings were analyzed. The negative and PSMs were compared according to the clinical and surgical variables. Multivariable logistic regression models were applied to analyze predictors of PSMs. Results: Eight hundred consecutive patients were evaluated. Seven hundred sixty-one (95.1\%) and 39 patients (4.9\%) achieved negative and PSMs, respectively. Patients with PSMs were significantly older compared with those with negative margins (median age: 66.6 vs. 61.8 years, respectively; $P=.001$ ). A higher incidence of PSMs was observed when NSS was performed for renal masses located in the upper pole $(P=.001)$. A lower rate of PSMs was found in patients treated with simple enucleation rather than standard PN $(1.6 \%$ vs. $7.4 \%$, respectively; $P<.0001)$. A greater incidence of PSMs was found in Fuhrman $3 / 4$ tumors $(11.3 \% ; P<.0001)$. At multivariable analysis, age (odds ratio [OR], 1.04; $P=.01$ ), upper pole tumor location (OR, 2.85; $P=.005$ ), standard $\mathrm{PN}$ (OR, 3.45; $P=.004)$, and Fuhrman 3-4 nuclear grade (OR, 4.81; $P=.001)$ were found to be independent predictors of PSMs. Conclusion: In our multi-institutional report, young age, simple enucleation, middle or lower tumor location, and low-grade tumor were demonstrated to be independent predictors of negative SMs.
\end{abstract}

Clinical Genitourinary Cancer, Vol. 13, No. 2, 165-70 @ 2015 Elsevier Inc. All rights reserved.

Keywords: Partial nephrectomy, Positive margin, Predictors, Renal cancer, Simple tumor enucleation

${ }^{1}$ Dipartimento di Urologia, Università di Bologna, Ospedale S. Orsola-Malpighi, Bologna, Italy

${ }^{2}$ Clinica Urologica I, AOUC, Università di Firenze, Italy

${ }^{3}$ Unità Operativa di Urologia Dipartimento di Nefro Urologia; Azienda AO Spedali

Civili di Brescia, Italy

${ }^{4}$ Divisione di Urologia, Università di Torino, Ospedale San Luigi Gonzaga, Orbassano,

Torino, Italy

${ }^{5}$ Policlinico di Modena, Clinica Urologica, Università di Modena, Italy

${ }^{6}$ Policlinico Federico II, Università di Napoli, Italia

${ }^{7}$ Luna Foundation

${ }^{8} \mathrm{UOC}$ urologia Ospedale maggiore ca' granda policlinico mangiagalli regina Elena Università degli studi di Milano, Milan, Italy
${ }^{9}$ I.R.C.C.S. Policlinico San Matteo - Struttura Di Urologia, Pavia, Italy

${ }^{10}$ Dipartimento di Urologia, Azienda Ospedaliera Maggiore della Carità, Novara, Italy ${ }^{11}$ Clinica Urologica, Università di Padova, Padova, Italy

Submitted: Mar 6, 2014; Revised: Aug 12, 2014; Accepted: Aug 25, 2014; Epub: Sep 23, 2014

Address for correspondence: Riccardo Schiavina, MD, Department of Urology, University of Bologna, S Orsola-Malpighi Hospital, Palagi 9, 40134 Bologna, Italy Fax: +390516362747; e-mail contact: rschiavina@yahoo.it 


\section{Predictors of PSMs After NSS}

\section{Introduction}

Nephron-sparing surgery (NSS) has become the standard of care for the conservative management of clinically localized renal cell carcinoma (RCC) whenever technically feasible, ${ }^{1,2}$ offering equivalent oncological results, ${ }^{3,4}$ and less renal function impairment ${ }^{5,6}$ compared with radical nephrectomy. The excision of the tumor with a minimal margin of healthy parenchyma surrounding the neoplasm is currently considered the standard technique for partial nephrectomy (PN), to minimize the risk of PSMs and achieve optimal local cancer control. ${ }^{1}$ In recent years, large series have reported the results of simple enucleation of renal masses showing functional and oncological results equivalent to standard PN. ${ }^{7}$ In all cases, NSS might result in incomplete cancer removal, thus causing PSMs, which might need additional follow-up and can lead to a potentially increased risk of local recurrence and disease progression. ${ }^{8-10}$ In the absence of randomized trials providing strong clinical evidence, several factors have been advocated as predictors of PSMs after NSS, such as tumor size, ${ }^{11}$ pathological stage, ${ }^{9}$ Fuhrman grade, ${ }^{12}$ indication for NSS (elective vs. imperative), ${ }^{11}$ and surgical volume. ${ }^{13}$ Conversely, the surgical approach (open vs. minimally invasive), and surgical technique (standard PN vs. SE), appear to be unrelated to margins status, according to the largest currently available evidence. ${ }^{7,14}$ We aimed to evaluate the predictors of PSM after NSS for RCC in one of the largest available prospective multi-institutional studies.

\section{Patients and Methods}

The Italian Registry of Conservative Renal Surgery (RECORd project) is a 4-year prospective observational multicenter study promoted by the Leading Urological Nonprofit Foundation Advanced Research of the Società Italiana di Urologia. The RECORd project includes all patients who underwent conservative surgical treatment for radiologically diagnosed kidney tumors between January 2009 and December 2012 at 19 urological Italian centers, upon the approval of the study protocol by the local ethical committee and patient acceptance of the written informed consent. Overall, data were collected on 1055 patients. In the present study only malignant lesions were analyzed and 255 (24.2\%) cases with benign histology were excluded. An online database was generated which comprised 5 main folders: (1) anthropometric and preoperative data; (2) imaging, indications, and comorbidities; (3) intraoperative data; (4) postoperative data; and (5) histological analysis. All data were centrally recorded on a data server. All preoperative anthropometric characteristics were collected: sex, age, and body mass index (BMI). Surgical indications were defined as elective (localized unilateral RCC with healthy contralateral kidney), relative (localized unilateral RCC with the coexistence of comorbidities such as diabetes, hypertension, or lithiasis that could potentially affect kidney function in the future), and absolute (bilateral tumors, multiple tumors, moderate to severe chronic kidney disease, or in case of neoplasia involving an anatomically or functionally solitary kidney). Performance status was assigned according to the Eastern Cooperative Oncology Group (ECOG) criteria. ${ }^{19}$ Mode of presentation was distinguished according to the Patard classification. ${ }^{20}$ In all patients, clinical workup included at least abdominal computed tomography (CT) scans and chest $\mathrm{x}$-rays. Chest and brain CT scans were obtained only when indicated according to signs and symptoms. Tumors were classified according to their location on the longitudinal plane (upper pole, middle part, and lower pole) and on the transverse plane (anterior surface, posterior surface, lateral margin, medial margin, perihilar) of the kidney. According to the degree of depth into the kidney, tumors were also subdivided into 3 growth pattern categories: (1) prevalently ( $\geq 50 \%$ ) exophytic; (2) prevalently endophytic $(<50 \%$ exophytic); and (3) entirely endophytic. All intraoperative data including center surgical volume, surgical approach and technique, the decision whether or not to clamp the renal vessels, type of ischemia, ischemia time, estimated intraoperative blood loss (EBL) and operative time were recorded. Analyzing the full data set of 1055 cases, centers were divided in low- and high-volume, and low and very high-volume according to the threshold of 50 and 65 interventions of NSS per year, respectively. The minimally invasive (video laparoscopic or robot-assisted) and open approaches and the surgical technique, performed in the form of standard PN and SE, were adopted according to the centers' and surgeons' preference. Standard PN has been defined as the excision of the tumor comprising a minimal margin of healthy peritumoral renal parenchyma. ${ }^{7}$ SE has been defined as blunt tumor excision without removing a visible rim of parenchymal tissue around the pseudocapsule. All surgical specimens were processed according to standard pathological procedures at each institution by experienced uropathologists. For surgical margin (SM) evaluation the specimens were fixed in $10 \%$ buffered formalin, and grossly analyzed. The size, color, gross aspect (solid to cystic) were recorded and the SM was marked with ink. After tumor dissection, samples were performed to obtain tissue blocks at tumor, healthy parenchyma, and surgical edges and further blocks with tumor, renal capsule, and peritumoral fat were enclosed. The margin was considered positive when tumor tissue was marked with ink. The margin was considered negative when no neoplastic renal tissue was observed on the inked edges. Tumors were pathologically staged according to the American Joint Committee on Cancer tumor, node, metastases classification. $^{21}$ The renal epithelial neoplasm classification, outlined in the 2004 World Health Organization monograph, was used to assign the histological type. ${ }^{22}$ The Fuhrman classification was used to assign the nuclear grade. ${ }^{22}$ No central pathological slide review was performed. All medical and surgical complications that occurred within 30 days from surgery were recorded. The severity of surgical complications was graded according to the modified Clavien system. ${ }^{23}$

\section{Statistical Analysis}

Categorical variables were reported as number and percentage. Continuous variables were reported as mean (SD) or as median and interquartile range (IQR), as appropriate. The Student $t$ test and the Mann-Whitney $U$ test were used to compare continuous variables and Pearson $\chi^{2}$ test was used to compare categorical variables. The negative SMs (NSMs) and PSMs were compared according to the clinical and surgical variables. Multivariable logistic regression models considering factors that were significantly related to SM status at univariable analysis were applied to analyze predictors of PSMs. Statistical significance in this study was set as $P \leq .05$. All reported $P$ values are 2 -sided. Analyses were performed using SPSS version 20.0 (SPSS Inc, Chicago, IL). 


\section{Results}

Overall, 800 patients were evaluated. In Table 1 the clinical characteristics of the entire cohort according to the SM status are reported: 761 (95.1\%) achieved NSMs, and 39 patients (4.9\%) had PSMs at the final pathological examination. Patients with PSMs were significantly older compared with those with NSMs (median age: 66.6 vs. 61.8 years, respectively; $P=.001$ ). Conversely, no statistically significant differences were found among patients with positive and negative margins in terms of sex, BMI, indication to NSS (elective/relative vs. imperative), symptoms at the time of diagnosis, ECOG performance status, number of lesions, clinical stage, and tumor side. Median (IQR) clinical diameter was 3.3 (2.3-4) $\mathrm{cm}$ and $3.2(2.0-3.9) \mathrm{cm}$ in patients with NSMs and PSMs, respectively $(P=.6)$. A significantly greater incidence of PSMs was observed when NSS was performed for renal masses located in the upper pole compared with mesorenal or lower pole tumors $(P=.001)$. On the contrary, the tumor growth pattern (exophytic/ endophytic) and localization (anterior, posterior, medial, lateral) did not significantly affect the SM status.

In Table 2 the most relevant intraoperative data are summarized. The incidence of PSMs was significantly lower after minimally invasive NSS compared with open procedures $(3.0 \%$ vs. $6.2 \%$ respectively; $P=.04)$. According to the adopted surgical technique, a lower rate of PSM was found in patients treated with SE rather than standard $\mathrm{PN}(1.6 \%$ vs. $7.4 \%$, respectively; $P<.0001)$. Conversely, margin status was not significantly affected by the center's surgical volume, considering low- versus high-volume centers and low- versus very high-volume centers. Margin status was not significantly affected by operative time, EBL, hilar clamping, ischemia time, and intraoperative complications. Furthermore, no significant differences in terms of tumor histotype, pathological diameter, and pathologic tumor evaluation (intracapsular vs. extracapsular) were found among patients with NSMs and PSMs, respectively (Table 3); interestingly, the incidence of PSMs was greater in Fuhrman 3/4 tumors compared with those with lower nuclear grade $(11.3 \%$ vs. $3.1 \%$, respectively; $P<.0001$; Table 3$)$.

Results from multivariable logistic regression analysis considering factors that were significantly related to SM status are summarized in Table 4. Age (odds ratio [OR], 1.04; $P=.01$ ), upper pole tumor location (OR, 2.85; $P=.005)$, standard PN (OR, 3.45; $P=.004)$, and Fuhrman $3 / 4$ nuclear grade $(\mathrm{OR}, 4.81 ; P=.001)$ were found to be independent predictors of PSMs. Conversely, the surgical approach (open vs. minimally invasive) was not an independent variable $(\mathrm{OR}, 1.36 ; P=.48)$ at multivariable analysis.

\section{Discussion}

When performing NSS for RCC, the complete removal of the tumor and the avoidance of PSMs is of paramount importance, to reach optimal long-term oncological control. ${ }^{1}$ Currently, the incidence of PSMs after elective NSS ranges from $0 \%$ to $7 \% .{ }^{10}$ Our series report an overall incidence of PSMs of $4.9 \%$, which is comparable to the results of other NSS series, regardless of the surgical approach (open vs. minimally invasive). ${ }^{9}$ To our knowledge, this is one of the largest, multi-institutional prospective studies to evaluate the predictors of PSMs and, to our knowledge, it is the first that included open and minimally invasive NSS in the analyses.
Table 1 Clinical Characteristics of the Entire Cohort of $\mathbf{8 0 0}$ Patients According to SM Status

\begin{tabular}{|c|c|c|c|}
\hline Preoperative Data & $\begin{array}{c}\text { Negative SM } \\
\text { (n= 761; } \\
95.2 \%)\end{array}$ & $\begin{array}{c}\text { Positive SM } \\
\text { (n = 39; } \\
4.8 \%)\end{array}$ & $\boldsymbol{P}$ \\
\hline \multicolumn{4}{|l|}{ Sex, n (\%) } \\
\hline Male & $524(94.9)$ & $28(5.1)$ & .70 \\
\hline Female & 237 (95.6) & $11(4.4)$ & \\
\hline \multicolumn{4}{|l|}{ Age } \\
\hline$<65$ Years, n (\%) & $406(96.4)$ & $15(3.6)$ & .07 \\
\hline$\geq 65$ Years, $n$ (\%) & $355(93.7)$ & $24(6.3)$ & \\
\hline Mean (SD), years & $61.8(12.6)$ & $66.6(8.8)$ & .001 \\
\hline Median BMI (IQR) & $28.7(24.3-28.5)$ & $26.3(23.8-27.7)$ & .29 \\
\hline \multicolumn{4}{|l|}{ Indication, $\mathbf{n}(\%)$} \\
\hline Elective/relative & 707 (95.4) & $34(4.6)$ & .18 \\
\hline Absolute & $54(91.5)$ & $5(8.5)$ & \\
\hline \multicolumn{4}{|l|}{$\begin{array}{l}\text { Symptoms at Diagnosis, } \\
\text { n (\%) }\end{array}$} \\
\hline Asymptomatic & $598(95.3)$ & $29(4.7)$ & .71 \\
\hline Symptomatic & $163(94.4)$ & $10(5.6)$ & \\
\hline \multicolumn{4}{|l|}{$\begin{array}{l}\text { ECOG Performance } \\
\text { Status, } \mathbf{n}(\%)\end{array}$} \\
\hline 0 & $531(95.7)$ & $24(4.3)$ & .28 \\
\hline$\geq 1$ & 230 (93.9) & $15(6.1)$ & \\
\hline \multicolumn{4}{|l|}{ Number of Lesions, $\mathbf{n}(\%)$} \\
\hline Single & $727(95.0)$ & $38(5.0)$ & .57 \\
\hline Multiple & $34(97.1)$ & $1(2.9)$ & \\
\hline $\begin{array}{l}\text { Median Clinical Diameter } \\
\text { (IQR) }\end{array}$ & $3.3(2.3-4.0)$ & $3.2(2.0-3.9)$ & .60 \\
\hline \multicolumn{4}{|l|}{$\begin{array}{l}\text { Clinical T Classification, } \\
\text { n (\%) }\end{array}$} \\
\hline T1a & 565 (95.6) & $30(4.4)$ & .93 \\
\hline$T 1 b$ & $176(95.7)$ & $8(4.3)$ & \\
\hline T2 & 20 (95.2) & $1(4.8)$ & \\
\hline \multicolumn{4}{|l|}{ Tumor Side, n (\%) } \\
\hline Right & $416(54.7)$ & $19(48.7)$ & .35 \\
\hline Left & $345(45.3)$ & $20(51.3)$ & \\
\hline \multicolumn{4}{|l|}{$\begin{array}{l}\text { Tumor Growth Pattern, } \\
\text { n (\%) }\end{array}$} \\
\hline$\geq 50 \%$ exophytic & 577 (94.4) & $34(5.6)$ & .22 \\
\hline$<50 \%$ exophytic & $167(97.7)$ & $4(2.3)$ & \\
\hline Entirely endophytic & $17(94.4)$ & $1(5.6)$ & \\
\hline \multicolumn{4}{|l|}{ Tumor Site, n (\%) } \\
\hline Polar superior & $206(90.7)$ & $21(9.3)$ & .001 \\
\hline Mesorenal & $303(97.4)$ & $8(2.6)$ & \\
\hline Polar inferior & $252(96.2)$ & $10(3.8)$ & \\
\hline \multicolumn{4}{|l|}{ Tumor Localization, n (\%) } \\
\hline Peri-hilar & $38(95.0)$ & $2(5.0)$ & .87 \\
\hline Anterior face & $230(94.3)$ & $14(5.7)$ & \\
\hline Posterior face & $217(96.0)$ & $9(4.0)$ & \\
\hline Medial margin & $68(97.2)$ & $2(2.8)$ & \\
\hline Lateral margin & 207 (94.5) & $12(5.5)$ & \\
\hline
\end{tabular}

Abbreviations: $\mathrm{BMI}=$ body mass index; $\mathrm{ECOG}=$ Eastern Cooperative Oncology Group; $\mathrm{IQR}=$ interquartile range; $\mathrm{SM}=$ surgical margin. 


\begin{tabular}{|c|c|c|c|}
\hline $\begin{array}{ll}\text { ble } 2 \text { Intraoperati } \\
\text { tients Accor }\end{array}$ & $\begin{array}{l}\text { ata of the E } \\
\text { to SM Stat }\end{array}$ & e Cohort c & $\mathrm{Pa}-$ \\
\hline Intraoperative Data & $\begin{array}{c}\text { Negative SM } \\
\text { (n = 761; } \\
95.2 \%)\end{array}$ & $\begin{array}{c}\text { Positive SM } \\
\text { (n = 39; } \\
4.8 \%)\end{array}$ & $\boldsymbol{P}$ \\
\hline \multicolumn{4}{|l|}{ Center Volume, n (\%) } \\
\hline High & $559(95.1)$ & $29(4.9)$ & .90 \\
\hline Low & $202(95.3)$ & $10(4.7)$ & \\
\hline \multicolumn{4}{|l|}{ Center Volume, n (\%) } \\
\hline Very high & $322(42.3)$ & $20(51.3)$ & .27 \\
\hline Low & $439(57.7)$ & $19(48.7)$ & \\
\hline \multicolumn{4}{|l|}{ Approach, $\mathbf{n}(\%)$} \\
\hline Open & $442(93.8)$ & $29(6.2)$ & .04 \\
\hline Minimally invasive & $319(97.0)$ & $10(3.0)$ & \\
\hline \multicolumn{4}{|l|}{ Technique, n (\%) } \\
\hline Simple enucleation & $306(98.4)$ & $5(1.6)$ & $<.0001$ \\
\hline Standard PN & $426(92.6)$ & $34(7.4)$ & \\
\hline $\begin{array}{l}\text { Median Operative } \\
\text { Time (IQR) }\end{array}$ & $130(105-175)$ & $147(105-185)$ & .49 \\
\hline Median EBL (IQR), mL & $190(100-300)$ & $200(100-300)$ & .77 \\
\hline \multicolumn{4}{|l|}{ Hilar Clamping, n (\%) } \\
\hline Not performed & $278(94.2)$ & $17(5.8)$ & .37 \\
\hline Performed & $483(95.6)$ & $22(4.4)$ & \\
\hline $\begin{array}{l}\text { Median Ischemia Time } \\
\text { (IQR), Minutes }\end{array}$ & $16(13-20)$ & $15(11-21)$ & .22 \\
\hline \multicolumn{4}{|l|}{$\begin{array}{l}\text { Intraoperative } \\
\text { Complications, n (\%) }\end{array}$} \\
\hline Present & $45(93.7)$ & $3(6.3)$ & .64 \\
\hline Absent & 716 (95.2) & $36(4.8)$ & \\
\hline
\end{tabular}

Abbreviations: $\mathrm{EBL}=$ estimated intraoperative blood loss; $\mathrm{IQR}=$ interquartile range; $\mathrm{PN}=$ partial nephrectomy; $\mathrm{SM}=$ surgical margin.

In our multi-institutional study, the PSM rate was slightly greater in patients treated with open rather than minimally invasive (either laparoscopic or robot-assisted) NSS at univariable analysis (6.2\% vs. $3.0 \%$, respectively; $P=.04)$. Conversely, the surgical approach failed to confirm its independent role as a predictor of PSM at multivariable analysis (Table 4). In a recent matched-pair analysis comparing open and robot-assisted PNs from 23 centers, Ficarra et al found no significant difference in PSM rate among open $(5.5 \%)$ and robot-assisted $(5.7 \%)$ PNs $(P=.98) .{ }^{16}$ Similarly, Springer and coworkers, showing results from a retrospective singleinstitutional study of 340 open and laparoscopic PNs for cT1 RCC, found comparable incidence of PSMs between the 2 groups $(1.7 \%$ vs. $1.2 \% ; P=.09){ }^{24}$

It appears still controversial whether the age at the time of surgery could be a predictor of PSMs. In our report, the rate of positive margins was found to be slightly greater in patients older than 65 years, even if these data were not statistically significant at univariable analysis (Table $1 ; P=.07$ ). Conversely, at the multivariable logistic regression analysis, age as a continuous value was demonstrated to be a significant and independent predictor of PSMs (OR, 1.04; $P=.01$; Table 4). Such a result could be easily explained. Basically, in older patients, renal function could be much more impaired because of medical or cardiovascular comorbidities than in
Table 3 Pathological Characteristics of the Entire Cohort of 800 Patients According to SM Status

\begin{tabular}{|c|c|c|c|}
\hline Pathological Data & $\begin{array}{l}\text { Negative SM } \\
\text { (n = 761; } \\
95.2 \%)\end{array}$ & $\begin{array}{c}\text { Positive SM } \\
\text { (n = 39; } \\
4.8 \%)\end{array}$ & $\boldsymbol{P}$ \\
\hline \multicolumn{4}{|l|}{ Histotype, n (\%) } \\
\hline Clear cell RCC & $550(95.3)$ & $27(4.7)$ & .75 \\
\hline Papillary RCC & $119(96.7)$ & $4(3.3)$ & \\
\hline Chromophobe RCC & 77 (96.2) & $3(3.8)$ & \\
\hline Unclassified RCC & $5(71.4)$ & $2(28.6)$ & - \\
\hline Other renal tumors ${ }^{\mathrm{a}}$ & $10(76.9)$ & $3(23.1)$ & - \\
\hline $\begin{array}{l}\text { Median Pathological } \\
\text { Diameter (IQR) }\end{array}$ & $3.0(2.4-4.0)$ & $3.0(2.2-4.0)$ & .84 \\
\hline \multicolumn{4}{|l|}{ Nuclear Grade, n (\%) } \\
\hline $1-2$ & $534(96.9)$ & $17(3.1)$ & $<.0001$ \\
\hline $3-4$ & $134(88.7)$ & $17(11.3)$ & \\
\hline \multicolumn{4}{|l|}{$\begin{array}{l}\text { Pathologic Tumor } \\
\text { Evaluation, n (\%) }\end{array}$} \\
\hline Intracapsular & 702 (95.5) & $33(4.5)$ & .07 \\
\hline Extracapsular & $56(90.3)$ & $6(9.7)$ & \\
\hline
\end{tabular}

Abbreviations: $I Q R=$ interquartile range; $\mathrm{RCC}=$ renal cell carcinoma; $\mathrm{SM}=$ surgical margin . aOther renal tumors: 8 multilocular cystic RCC, 1 sarcomatoid RCC, 2 translocation carcinoma (microphthalmia transcription factor/transcription factor $\mathrm{E}$ family translocation-associated carcinoma), 1 mucinous tubular and spindle cell carcinoma, 1 thyroid-like follicular carcinoma of the kidney.

their younger counterparts. In this scenario, urologists attempt to spare as much healthy parenchyma as possible during NSS, to minimize the loss of postoperative renal function, thus increasing the risk of PSMs. This result is different than others reported in the literature. Ani et al found that age was not independently associated with the higher risk of PSMs at multivariable analysis (OR, 0.99; $P=.3){ }^{9}$ Similarly, Yossepowitch and coworkers did not find any correlation between age and SM status at univariable (OR, 1; $P=.77)$ and multivariable (OR, $1 ; P=.81)$ analysis. ${ }^{11}$

Despite the previous, historical recommendations to remove at least $1 \mathrm{~cm}$ of normal-appearing renal parenchyma around the tumor to ensure negative margins, ${ }^{25}$ the current indications for NSS have progressively changed: indeed, according to the recognized oncological safety of NSS even for T1b RCC, 3,26 and to the need for preservation of as much functioning healthy parenchyma as possible to minimize the loss of renal function, ${ }^{27}$ NSS has moved from maximal parenchymal resection to minimal tissue removal. ${ }^{20}$ In this

\section{Table 4 Multivariable Logistic Regression Models Accounting for the Significant Predictors of PSM}

\begin{tabular}{|c|c|c|c|}
\hline Multivariate Analysis for PSM & OR & $95 \% \mathrm{CI}$ & $\boldsymbol{P}$ \\
\hline Continuous Variable, Age, Year & 1.04 & $1.00-1.08$ & .01 \\
\hline $\begin{array}{l}\text { Polar Superior Lesion Tumor Site } \\
\text { versus Others }\end{array}$ & 2.85 & $1.37-5.87$ & .005 \\
\hline Standard PN Technique versus SE & 3.45 & $1.66-7.19$ & .004 \\
\hline $\begin{array}{l}\text { Open Approach versus Minimally } \\
\text { Invasive Approach }\end{array}$ & 1.36 & $0.58-3.19$ & .48 \\
\hline Nuclear Grade 3/4 versus 1/2 & 4.81 & $1.63-14.16$ & .001 \\
\hline
\end{tabular}

Abbreviations: $\mathrm{PN}=$ partial nephrectomy; $\mathrm{PSM}=$ positive surgical margin; $\mathrm{SE}=$ simple enucleation. 


\section{Riccardo Schiavina et al}

scenario, several nonrandomized studies demonstrated the oncological safety of simple tumor enucleation compared with standard PN for the treatment of cT1 RCC, with a quite lower incidence of PSMs with respect to those observed after standard PN. ${ }^{7,28,29}$ Minervini et al, in the retrospective SATURN (Surveillance And Treatment Update Renal Cancer) study, found a PSM rate of $0.2 \%$ and $3.4 \%$ after SE and traditional PN, respectively $(P<.001)$. Similarly, in our study the incidence of PSM was significantly less in patients treated with SE $(P<.0001$; Table 1$)$, even in multivariable analysis the surgical technique was confirmed as an independent predictor of PSM (OR, 3.45; $P=.004$; Table 4). The reason of such a result, however, should be carefully analyzed. In fact, the blunt enucleation of the tumor along the inflammatory pseudocapsule, rather than a traditional resection of the surrounding healthy parenchyma, could allow to a better respect the natural cleavage plane, avoiding entering the mass in case of irregular shape and leaving positive margins behind. Moreover, extensive and established experience of surgeons performing SE in this series could be another possible explanation of such a result. Therefore, the present data should be regarded as a proof of noninferiority in terms of local cancer control of SE versus standard PN but prospective randomized series are awaited to shed light on this oncological issue.

Longitudinal location (polar vs. mesorenal), exophytic, hilar location, and clinical dimension of the tumor (parameters that belong to the preoperative aspects and dimensions used for an anatomical classification of renal tumors) ${ }^{30}$ could be significant preoperative factors able to predict the complexity of the NSS and could be related to the risk of complications and of PSMs. It seems reasonable that, the higher is the surgical complexity, the more challenging it is to achieve local control and complete resection. In our study, the rate of PSMs after NSS was significantly greater only for upper polar tumors, rather than mesorenal or lower polar lesions ( $9.3 \%$ vs. $2.6 \%$ vs. $3.8 \%$, respectively; $P=.001)$. Moreover, the polar location (superior vs. mesorenal/inferior) was demonstrated to be an independent predictor of PSMs in multivariable analysis (OR, 2.85; $P=.005$; Table 4). A worse exposure of the surgical field in the upper pole tumors in right- and left-side tumors might render the resection of the tumor more difficult, especially when performing minimally invasive procedures. To our knowledge, no previous series reported a correlation between tumor polar location and the risk of PSMs. Nevertheless, in the present series, the rate of PSMs was not influenced by the tumor growth pattern, the hilar location, and the rim location. This agrees with the data reported in other recently published articles. Khalifeh and coworkers, in a multi-institutional, retrospective study of 943 consecutive robotassisted PNs, showed that SM status was not significantly compromised by the hilar location, endophytic rate, or the tumor complexity according to the nephrometric score. ${ }^{8}$

Currently, there are no convincing correlations among tumor size, clinical stage, and incidence of PSM after NSS. Yossepowitch et al retrospectively evaluated a cohort of 1390 patients with a mean tumor diameter of $3.5 \mathrm{~cm}$, demonstrating that increasing tumor size was associated with a lower incidence of positive margins in univariate and multivariate analyses $(P=.05) .{ }^{11}$ Conversely, a comparable incidence of PSMs between patients with tumors $\leq 4 \mathrm{~cm}$ and $>4 \mathrm{~cm}$ has been found in other retrospective open and laparoscopic series. ${ }^{31,32}$ In a recent report from the Ontario Cancer
Registry that evaluated 788 open and laparoscopic PNs, Ani et al found significant correlations between increasing tumor size and margin status, with a 4-fold higher risk of PSM in pT1b tumors $(P=.002) .{ }^{9}$ In our study the mean tumor dimension and the clinical and pathological stage failed to correlate with PSM status. This finding corroborates the oncological safety of NSS even in cT1b renal tumors, regardless of the surgical approach and technique adopted.

The correlation between high nuclear grade and the incidence of PSMs still remains controversial. Intuitively, the presence of a more aggressive and infiltrative cancer with an irregular shape and infiltrative growth pattern might render the tumor dissection more challenging, thus enhancing the incidence of PSMs. Higher nuclear grade and more unfavorable cancers have been shown to be related to the complexity of the renal tumors, according to their anatomic and topographic characteristics. ${ }^{33}$ In the present study, positive margins were significantly greater in patients with Fuhrman 3/4 RCC compared with those with nuclear grade $1 / 2(P<.0001)$. Furthermore, higher tumor grade was found to be an independent predictor of PSM at multivariate analysis (OR, 4.81; $P=.001$; Table 4). Bensalah et al retrospectively evaluated a cohort of 775 patients treated with PN and found comparable results: a greater frequency of high-grade tumors was found in patients with PSMs rather than in those with NSMs (30\% vs. $19.4 \%$, respectively). ${ }^{12}$ Contrasting results have been recently reported in other studies, ${ }^{8}$ in which nuclear grade was neither associated nor an independent predictor of PSMs.

In the literature, the surgical indication (elective/relative vs. imperative) was demonstrated to play a role in the prediction of PSMs after PN. Yossepowitch et al, after adjusting for clinical tumor size, found that the imperative indication was an independent predictor of PSMs. ${ }^{11}$ Conversely, in the present study the incidence of PSMs was not statistically influenced by the surgical indication. Indeed, even if the rate of positive margins was greater in patients treated with imperative NSS (8.5\%) compared with those who received an elective procedure $(4.6 \%)$, this finding did not reach the statistical significance $(P=.18)$. However, the low number of patients treated with imperative indications in our report could have reduced the statistical power of our analysis.

The actual clinical and oncological effect of PSMs after NSS is controversial. Indeed, according to the currently available evidence, ${ }^{10}$ the presence of a positive margin could lead to a higher risk of local recurrence in the ipsilateral kidney, especially in patients with highgrade tumors. Conversely, at intermediate- and long-term followup, the metastatic progression and cancer-specific mortality rates were found to be comparable among patients with PSMs or NSMs. ${ }^{10}$

We believe that the larger number of patients treated and variables analyzed, and the prospectively maintained database are the main strengths of our study. Moreover, its multicenter nature might increase the external validity of the data compared with the singlecenter, single-surgeon setting and provide a valid snapshot of the incidence and predictors of PSMs in a European country in the past 4 years. As study limitations, the absence of a central pathological review, which would have influenced the interpretation of the specimens and the final diagnosis of SM status, and the lack of assessment of the surgical complexity according to nephrometric scores represent the most important limitations of the present study. 


\section{Predictors of PSMs After NSS}

\section{Conclusion}

The early oncological goal of PN is to achieve negative margins. In our multi-institutional report of open and minimally invasive NSS, the overall rate of PSMs was $4.9 \%$. Older age, standard PN technique, upper polar tumor location, and high-grade tumor were all independent predictors of PSMs. Further evaluation and followup is required to verify the oncological effect of the PSM on local and systemic recurrence.

\section{Clinical Practice Points}

- The excision of the tumor with a minimal margin of healthy parenchyma surrounding the neoplasm is currently considered the standard technique for PN, to minimize the risk of PSMs and achieve optimal local cancer control.

- This study (RECORd project) includes all patients who underwent conservative surgical treatment for radiologically diagnosed kidney cancers between January 2009 and December 2012 at 19 Italian urological centers.

- Results from multivariable logistic regression analysis showed that age (OR, 1.04; $P=.01)$, upper pole tumor location (OR, 2.85; $P=.005)$, standard PN (OR, 3.45; $P=.004)$, and Fuhrman $3 / 4$ nuclear grade (OR, $4.81 ; P=.001)$ were found to be independent predictors of PSMs.

- Conversely, the surgical approach (open vs. minimally invasive) was not an independent variable $(\mathrm{OR}, 1.36 ; P=.48)$ at multivariable analysis.

- Further evaluation and follow-up is required to verify the oncological effect of the PSM on local and systemic recurrence.

\section{Disclosure}

The authors have stated that they have no conflicts of interest.

\section{References}

1. Ljungberg B, Cowan NC, Hanbury DC, et al. EAU guidelines on renal cell carcinoma: the 2010 update. Eur Urol 2010; 58:398-406.

2. Campbell SC, Novick AC, Belldegrun A, et al. Guideline for management of the clinical T1 renal mass. I Urol 2009; 182:1271-9.

3. MacLennan S, Imamura M, Lapitan MC, et al. Systematic review of oncological outcomes following surgical management of localized renal cancer. Eur Urol 2012; 61:972-93.

4. Van Poppel H, Da Pozzo L, Albrecht W, et al. A prospective, randomised EORTC intergroup phase 3 study comparing the oncologic outcome of elective nephronsparing surgery and radical nephrectomy for low-stage renal cell carcinoma. Eur Urol 2011; 59:543-52.

5. Kim SP, Thompson H, Boorjan SA, et al. Comparative effectiveness for survival and renal function of partial and radical nephrectomy for localized renal tumors: a systematic review and meta-analysis. J Urol 2012; 188:51-7.

6. Scosyrev E, Messing EM, Sylvester R, Campbell S, Van Poppel H. Renal function after nephron-sparing surgery versus radical nephrectomy: results from EORTC randomized trial 30904. Eur Urol 2014; 65:372-7.

7. Minervini A, Ficarra V, Rocco F, et al. Simple enucleation is equivalent to traditional partial nephrectomy for renal cell carcinoma: results of a nonrandomized, retrospective, comparative study. J Urol 2011; 185:1604-10.
8. Khalifeh A, Kaouk JH, Bhayani S, et al. Positive surgical margins in robot-assisted partial nephrectomy: a multi-institutional analysis of oncologic outcomes (leave no tumor behind). J Urol 2013; 190:1674-9.

9. Ani I, Finelli A, Alibhai SM, et al. Prevalence and impact on survival of positive surgical margins in partial nephrectomy for renal cell carcinoma: a populationbased study. BJU Int 2013; 111:E300-5.

10. Borghesi M, Brunocilla E, Schiavina R, et al. Positive surgical margins after nephron-sparing surgery for renal cell carcinoma: incidence, clinical impact, and management. Clin Genitourin Cancer 2013; 11:5-9.

11. Yossepowitch O, Thompson RH, Leibovich BC, et al. Positive surgical margins at partial nephrectomy: predictors and oncological outcomes. J Urol 2008; 179: 2158-63.

12. Bensalah K, Pantuck AJ, Rioux-Leclercq N, et al. Positive surgical margin appears to have negligible impact on survival of renal cell carcinomas treated by nephronsparing surgery. Eur Urol 2010; 57:466-71.

13. Couapel JP, Bensalah K, Bernhard JC, et al. Is there a volume-outcome relationship for partial nephrectomy? World J Urol 2014; 32:1323-9.

14. Zhang X, Shen Z, Zhong S, et al. Comparison of peri-operative outcomes of robot-assisted vs laparoscopic partial nephrectomy: a meta-analysis. BJU Int 2013; $112: 1133-42$.

15. Aboumarzouk OM, Stein RJ, Eyraud R, et al. Robotic versus laparoscopic partial nephrectomy: a systematic review and meta-analysis. Eur Urol 2012; 62:1023-33.

16. Ficarra V, Minervini A, Antonelli A, et al. A multicenter matched-pair analysis comparing robot-assisted versus open partial nephrectomy. BJU Int 2014; 113: 936-41.

17. Minervini A, Siena G, Antonelli A, et al. Open versus laparoscopic partial nephrectomy for clinical T1a renal masses: a matched-pair comparison of 280 patients with TRIFECTA outcomes (RECORd Project). World J Urol 2014; 32:257-63.

18. Borghesi M, Schiavina R, Gan M, et al. Expanding utilization of robotic partial nephrectomy for clinical T1b and complex T1a renal masses. World J Urol 2013; 31:499-504.

19. Oken MM, Creech RH, Tormey DC, et al. Toxicity and response criteria of the Eastern Cooperative Oncology Group. Am J Clin Oncol 1982; 5:649-55.

20. Patard JJ, Leray E, Cindolo L, et al. Multi-institutional validation of a symptom based classification for renal cell carcinoma. J Urol 2004; 172:858-62.

21. Greene FL, Page DL, Fleming ID, et al. American Joint Committee on Cancer (AJCC) Staging Manual. 6th edition. Philadelphia: Springer; 2002.

22. Eble JN, Sauter G, Epstein JI, et al, eds. In: Pathology and genetics of tumours of the urinary system and male genital organs. World Health Organization Classification of Tumours. Lyon: IARC Press; 2004:9-87.

23. Dindo D, Demartines N, Clavien PA. Classification of surgical complications: new proposal with evaluation in a color of 6336 patients and result of a survey. Ann Surg 2004; 240:205-13.

24. Springer C, Hoda MR, Fajkovic H, et al. Laparoscopic vs open partial nephrectomy for T1 renal tumours: evaluation of long-term oncological and functional outcomes in 340 patients. BJU Int 2013; 111:281-8.

25. Uzzo RG, Novick AC. Nephron-sparing surgery for renal tumors: indications, techniques and outcomes. J Urol 2001; 166:6-18.

26. Meskawi M, Becker A, Bianchi M, et al. Partial and radical nephrectomy provide comparable long-term cancer control for T1b renal cell carcinoma. Int J Urol 2014; 21:122-8.

27. Kaushik D, Kim SP, Childs MA, et al. Overall survival and development of stage IV chronic kidney disease in patients undergoing partial and radical nephrectomy for benign renal tumors. Eur Urol 2013; 64:600-6.

28. Carini M, Minervini A, Masieri L, et al. Simple enucleation for the treatment of PT1a renal cell carcinoma: our 20-year experience. Eur Urol 2006; 50:1263-8.

29. Carini M, Minervini A, Lapini A, et al. Simple enucleation for the treatment of renal cell carcinoma between 4 and $7 \mathrm{~cm}$ in greatest dimension: progression and long-term survival. J Urol 2006; 175:2022-6.

30. Ficarra V, Novara G, Secco S, et al. Preoperative aspects and dimensions used for an anatomical (PADUA) classification of renal tumours in patients who are candidates for nephron-sparing surgery. Eur Urol 2009; 56:786-93.

31. Patard JJ, Pantuck AJ, Crepel M, et al. Morbidity and clinical outcome of nephron-sparing surgery in relation to tumour size and indication. Eur Urol 2007 . 52:148-54

32. Porpiglia F, Fiori C, Bertolo R, et al. Does tumour size really affect the safety of laparoscopic partial nephrectomy? BJU Int 2011; 108:268-73.

33. Kutikov A, Smaldone MC, Egleston BL, et al. Anatomic features of enhancing renal masses predict malignant and high-grade pathology: a preoperative nomogram using the RENAL nephrometry score. Eur Urol 2011; 60:241-8. 